\title{
Care and Protection against Child Abuse: With Special Reference to Malaysia Child Act 2001
}

\author{
Tengku Fatimah Muliana binti Tengku Muda \\ Lecturer, Faculty of Islamic Contemporary Studies, University Sultan Zainal Abidin \\ Gong Badak Campus, 21300 Kuala Terengganu, Malaysia \\ Tel: 60-17-908-5152Ｅ-mail: tg_fatimah@unisza.edu.my \\ Dr. Engku Ahmad Zaki bin Engku Alwi (Corresponding author) \\ Ass. Prof., Faculty of Islamic Contemporary Studies, University Sultan Zainal Abidin \\ Gong Badak Campus, 21300 Kuala Terengganu, Malaysia \\ Tel: 60-17-9876-6936 E-mail: drkuzaki@unisza.edu.my
}

Received: May 8, 2011 Accepted: July 14, $2011 \quad$ Published: January 1, 2012

doi:10.5539/ass.v8n1p202

URL: http://dx.doi.org/10.5539/ass.v8n1p202

\begin{abstract}
All children have the right to live in an environment free from abuse and neglect. The safety of children is the paramount concern that must guide child protection efforts. It is in this context that reference of this paper will be made to The Child Act 2001, the key outcome of Malaysia's ratification of the Convention on the Rights of the Child (CRC) which forms part of the protective legal environment for children in the country. Initiatives have been introduced under this Act to safeguard children from abuse, neglect and violence such as incest which has been criminalized by the Penal Code and the Domestic Violence Act which protects the child against violence within family. This Act was introduced to consolidate and amend the laws relating to the care, protection and rehabilitation of children. With the Act beforehand, numbers of child abuse cases are still alarming. Therefore, this article is an attempt to give an overview of care and protection provided under the Child Act 2001 towards children who are being the victims of abuse. The main purpose of this article is to evaluate the extent of the protection and care given under the Act to safeguard the children in the social justice system in Malaysia. At the end of the paper some areas are identified for further improvement and future amendment.
\end{abstract}

Keywords: Care, Protection, Child, Malaysia Child Act 2001

\section{History of Child Maltreatment}

The phenomenon of child maltreatment or child abuse has a long history. Throughout the centuries, infanticide, or the killing of the young children, was an established social custom practiced with great frequently in many cultures. It served as a method of population control, although war, famine, epidemic, and accident proved more effective in limiting the number of citizens. According to the census figures in ancient Greece, for example, the ratio of male to female was four to one. Frequently only one daughter was spared in the family, while sons were rarely put to death. Infanticide is believed to have been the single most common crime of the Middle Ages and Renaissance. For a time during the Italian Renaissance, an estimated $50 \%$ of all babies were abandoned to die or be rescued by orphanages or procurers. The killing of illegitimate babies was also commonplace in Western societies for centuries. In some societies, it was against the law for an illegitimate child to be permitted to live; in other cultures the stigma associated with illegitimacy was so great that unwed mothers routinely eliminated the tangible symbol of their sinfulness. For the very poor, another mouth to feed could mean the difference between family survival and starvation for all; therefore, infanticide provided the course many chose. The practice remained prevalent well into sixteenth century and even today is common in some isolated cultures. In certain societies, deformed children were put to death as soon as the imperfections were discovered. Infanticide viewed as religious duty was also an established custom in many past societies. Although church law prohibited infanticide, legislation was inconsistent at the state level, and prosecution was rare. The methods employed 
throughout history to accomplish infanticide include the drowning, burning, strangling or smothering, poisoning, beating and abandoning of children. Generally, infanticide occurred without bloodshed, except for occasional ritualistic practices in which bloodletting was an important element (Note 1).

Yet it is not surprising that in the modern society, child maltreatment is still of common. The present concern of child abuse in Malaysia can be traced back to the case of Balasundram, an innocent child aged 26 months that had been abused and eventually suffered to death This case was the turning point that gave rise to the Child Protection Act 1991 which is the epitome of Malaysian legislative prowess, for it has transcended the boundaries of a mere description of the circumstances in which a child is in need of protection to a reasoned definition of the major aspects of child abuse itself. Since the introduction of this Act, and later the improved Child Act 2001, numerous actions and policies have been done in an effort to curb child abuse. The case of Balasundram was only the reflection of hundreds more under reported cases that have been going on undiagnosed and undetected by the public at large.

Statistic of the Malaysian Royal Police showed that child abuse, molestation and rape are on the increase, from 2236 cases in 2005 to 5744 cases in 2008. In 2009 from January to July, a total of 2193 cases of child abuse were reported, an average of 313 cases per month. The numbers were alarming, since international experience suggests that reported cases are likely to represent only 10 percent of total cases perpetrated.

As to apprehend the root of the problem since its early existence, it is perhaps better for us to examine the history of customary belief regarding the creation of a child in three leading races in Malaysia; Malay, Chinese and Indian.

\subsection{Customary belief}

Among the Malay community, every birth regardless a boy or a girl is a gift bestowed upon them, and culture plays an important role in the bringing up of the child. An old Malay saying goes; 'biar mati anak jangan mati adat' which bears the meaning, to let go a custom is far worse than to let go a child! It explains why custom is given such a high rank among Malays. It is hence apparent that custom binds the Malays, and they are willing to do anything for the sake of pride and custom. During the old days, there was not much heed given on the learning system among the Malays, rather, it went unplanned. Parents would only give their unconditional attention to the well-being of their children, prepared the clothing and food, and showered them with love until they became adult. This might be due to the environment and lack of awareness among the parents of the importance of education, particularly with the life in the rural community where most parents were from non-education background and illiterate. If ever they let the children to go to school, it was only for boys, since girls by then were only expected to be an obedient wife.

Yet, despite of not being educated, cases of child being physically abused or the object of the parent's sexual satisfaction were seldom heard. Children were given freedom to enjoy the upbringing process side by side customary guidelines.

The Chinese believe that a son carries the good name of the family whenever he goes. This is why researches indicate that there are fewer boys being abused among the Chinese community as compared to girls. Boys are always given special treat, whether in the development of his mental and physical health, or even in the learning process and career.

Horoscope indulgence among the Chinese community determines the prosperity of a person. According to the horoscope, certain animal represents a person thus influencing their character and their future accomplishment. Some animals do not fit to each other, and if the two animals happened to be together, it is considered as bad signs for their future undertakings. As for instance, a tiger and a pig do not match to one another, thus it is not a good sign if a child is born under the year whilst the mother is under the year of pig, since both are not fit to be together. It is believed as a sign of bad luck, and something had to be done in order to separate them. This kind of cultural belief wills doubtlessly affects the relationship and affection between the family members, and there is possible risk for an abuse to take place. The Chinese also believe that if a misfortune happens following the birth of one family member, that child will be responsible for it, and is also believed to bring bad luck in the family (Note 2). Accepted child-rearing practices among Chinese during the previous ages were often abusive. In such cases, children were the victims of the ignorance of their parents. For example, the custom of swaddling children was common for centuries even throughout other countries of the world. Children were tightly wrapped in clothe for their first year of life. Such treatment completely restricted their movements, sometimes cut off circulation to parts of their body. (Note 3) 
The history of Indians community also left the trace of child abuse since long. In Indian's belief, if a child is born between $14^{\text {th }}$ April to $14^{\text {th }}$ May or between $14^{\text {th }}$ July to $14^{\text {th }}$ August, he or she will be considered as bringing misfortune to the family. Typically, the Indians will try to hinder from giving births to their children on the said dates. And if a child is delivered on that particular dates, it is believed that there is a high risk for the baby to live in danger throughout his life. (Note 4)

With the history beforehand, violence against children seems to be existed in every country of the world, regardless of time, culture, rank, ethnic origin and religion.

\subsection{Defining Child and Child Abuse}

The earliest legislation governing child protection was the Children Enactment 1992 (Note 5) and a child entitled to protection under this Enactment must be below fourteen years (Note 6). Under the later Children Ordinance 1927 (Note 7) the definition of child from fourteen years was extended to sixteen years in a case of a person employed or engaged for or in connection for any public entertainment (Note 8); specifying the various categories of children based on the activities they indulged in. In 1947, the Children and Young Persons Act introduced a new definition of 'young person' as a person above the age of fourteen and under the age of eighteen. It is also incorporated in the later Age of Majority Act 1971, that every male and female attaining the age of 18 is considered as attaining the age of majority, subject to section 4 of the Act that reads 'any provision in any written law contained fixing the age of majority for the purposes of that written law'.

With several existing enactments governing the children, The Child Act 2001 (Act 611) is enforced in the best interest of the children and offers a more comprehensive protection on them. The Act also defines a child as person under the age of 18. Although the term abuse is not defined in the Act, section 17(2) set out the instances of abuse including physical abuse, neglect, sexual abuse, and emotional abuse.

It reads that a child is physically injured if there is substantial and observable injury to any part of the child's body as a result of the non-accidental application of force or an agent to the child's body that is evidenced by, amongst other things, a laceration, a contusion, an abrasion, a scar, a fracture or other bone injury, a dislocation, a sprain, haemorrhaging, the rupture of a viscus, a burn, a scald, the loss or alteration of consciousness or physiological functioning or the loss of hair or teeth.

A child is emotionally injured if there is substantial and observable impairment of the child's mental or emotional functioning that is evidenced by, amongst other things, a mental or behavioural disorder, including anxiety, depression, withdrawal, aggression or delayed development.

A child is sexually abused if he has taken part, whether as a participant or an observer, in any activity which is sexual in nature for the purposes of any pornographic, obscene or indecent material, photograph, recording, film, videotape or performance; or sexual exploitation by any person for that person's or another person's sexual gratification. It seems therefore difficult to precisely define the child abuse since it connotes cruelty, maltreatment and violence in varied forms, circumstances and concepts.

\section{Care and Protection under the Child Act 2001 (Act 611)}

It is in this context that reference will be made to The Child Act 2001, the key outcome of Malaysia's ratification of the Convention on the Rights of the Child (CRC) which forms part of the protective legal environment for children in the country. Initiatives have been introduced under this Act to safeguard children from abuse, neglect and violence such as incest which has been criminalized by the Penal Code and the Domestic Violence Act which protects the child against violence within family. This Act was introduced to consolidate and amend the laws relating to the care, protection and rehabilitation of children. The Child Act has led to the repeal of the Juvenile Courts Act 1947, the Women and Girls Protection Act 1973 and the Children Protection Act 1991.

As has been discussed earlier, Act 611 does not define 'child abuse' per se, rather, it recognizes different types of abuse. Section 17(1) of the Act further provides a detailed list of a child in need of care and protection, among others:

(a) the child has been or is under substantial risk of being physically or emotionally injured, or sexually abused by his /her parent, guardian or family member;

(b) the child has been or is under substantial risk of being physically or emotionally injured, or sexually abused and the child's parent or guardian, knowing about this, has not protected or is unlikely to protect the child from such injury or abuse;

(c) there is such a conflict between the child and his parent or guardian, or between his parents or guardians, that family relationships are seriously disrupted, thereby causing him emotional injury; 
(d) the child is or may have been the victim of any of the offences in the First Schedule of the Act and his parent or guardian has committed or is suspected to have committed the offence, or has not protected or is unlikely to protect the child from such offence; or

(e) the child lives in the same household as either the victim or the offender in (c) above and appears to be in danger of a similar offence, and his parent or guardian has committed or may have committed the offence or is unable or unwilling to protect the child from such offence.

\subsection{Duty to Report as an Essential Protection}

The concern on the duty to report as a preliminary steps to protect child abuse has been initiated in the early 1960 's to the view of Henry Kempe, an American pediatrician. He proved that a large number of the supposedly accidental injuries for which children were treated in hospitals were deliberately inflicted. (Note 9) Respectively, statutory duties are laid upon medical officers, family members and child care providers to report suspected case of child abuse under the Act 611. In the light of section 27, if a medical officer or a registered medical practitioner believes on reasonable grounds that a child he is examining or treating is physically or emotionally injured as a result of being ill-treated, neglected, abandoned or exposed, or is sexually abused, he shall immediately inform a Protector. Failure to comply with this provision is an offence punishable, upon conviction, to a fine not exceeding five thousand ringgit or to imprisonment for a term not exceeding two years or to both. A medical officer may take the child into temporary custody until such time as the temporary custody of the child is assumed by a Protector or police officer.

In the event of a report lodged but the child later proved not to have been abused, no charge can be made against the informer by the parents. In the case of D v National Society Prevention of Cruelty to Children [1978] AC 171 Lord Diplock observed that;

The rationale of the rule as it applies to police informers is plain. If their family were liable to be disclosed in court of law, these sources of information would dry up and the police would be hindered in their duty of preventing and detecting crimes. So the public interest in preserving the anonymity of police informers had to be weighed against the public interest that information which might assist a judicial tribunal to ascertain facts relevant to an issue upon which it is required to adjudicate should be withheld from that tribunal. By the uniform practice of the judges which by the time of Mark $v$ Beyfus had already hardened into a rule of law, the balance has fallen upon the side of non-disclosure except where upon a trial of a defendant for a criminal offence disclosure of the identity of the informer could help to show that the defendant was innocent of the offence. In that case, and in that case only, the balance falls upon the side of disclosure.

Off late, there have also been academic discourses suggesting that the mandatory obligation imposed on doctors, family members and child care providers should be extended to cover educators and other groups that come into constant contact with children to report to the relevant authorities in cases of suspected child abuse. (Note 10) Children and adolescents spend a large portion of their time in school, which gives educators more access to students than most other professionals. It enables the educators to detect any signs of bruises, scars or any signs of occurrence of abuse. The educators have also a professional and legally mandated responsibility for reporting suspected maltreatment. Thus the roles of the educators are crucial in combating the problem of child abuse and maltreatment.

\subsection{Temporary Custody and Medical Treatment}

In view of section 18, a Protector (Note 11) or police officer who is satisfied on reasonable grounds that a child is in need of care and protection may take the child into temporary custody, provided that it is for the best interest of the child. However as explained by Dunn LJ in $G v G$ [1982] Fam Law 184, it is extremely dangerous to place decisive weight upon the wishes of children at the age of twelve who are extremely suggestible and reluctant to upset their parents and are very protective towards them. The expression 'welfare of the child' further explained by Lindley LJ in McGrath [1893] 1 Ch 143 at p.148 as follows:

But the welfare of the child is not to be measured by money only, nor by physical comfort only. The word welfare must be taken in its widest sense. The moral and religious welfare of the child must be considered as well as its physical well being. Nor can the ties of affection be disregarded... 
The child may as well be placed in a place of safety or in the custody of a relative or other fit and proper person on such terms and conditions as the Protector may require until the child attains the age of eighteen years or for any shorter period. (Note 12) If in the opinion of the Protector or police officer the child needs medical examination or treatment, he or she may either take the child to a medical officer or direct the child's caregiver to do so. The Protector or police officer may also authorize the child's hospitalization and any medical, surgical or psychiatric treatment needed if there is immediate risk to the health of the child.

If in the opinion of a medical officer, the child is suffering from a serious illness, injury or condition or requires surgery or psychiatric treatment, a Protector or police officer may consult the parent or guardian of the child to consent to such treatment.

If the consent cannot be obtained, or if there is immediate risk to the health of the child the Protector may authorised such treatment as may be considered necessary by the medical officer.

\subsection{Powers of the Court for Children}

The statutory establishment of the Court for Children marks another protection against child abuse. Section 30(1) of the Act provides for the power of the Court in making orders. It reads that if a Court For Children is satisfied that any child is a child in need of care and protection, the Court For Children may, inter alia:

(a) order his parent or guardian to execute a bond to exercise proper care and guardianship for a period specified by the Court For Children;

(b) make an order placing the child in the custody of a fit and proper person for a period specified by the Court For Children;

(c) without making any other order or in addition to an order made under paragraph (a) or (b), make an order placing the child under the supervision of a Protector; or some other person appointed for the purpose by the Court For Children, for a period specified by the Court For Children;

(d) make an order placing the child in a place of safety for a period of three years from the date of the order or until he attains the age of eighteen years, whichever is the shorter; or

(e) in the case of a child who has no parent or guardian, make an order placing the child in the care, custody and control of a foster parent found to be suitable by the Director General for a period of two years or until he attains the age of eighteen years, whichever is the shorter, and pending that, place the child in a place of safety.

\subsection{Punishable Offences and Penalties}

The Child Act provides for a number of offences but if the abuse is severe, the Penal Code which carries harsher penalties is used. Section 31 of the Child Act makes it an offence if a person having the care of the child abuses, neglects, abandons or exposes the child in a manner likely to cause him physical or emotional injury; or sexually abuses the child or causes or permits him to be so abused, commits an offence and shall on conviction be liable to a fine not exceeding twenty thousand ringgit or to imprisonment for a term not exceeding ten years or to both.

In the case of $R$. v Hayles [1969] All ER 3, Widgery LJ made an explanation to the words 'willfully assaults, ill-treats, neglects, abandons or exposes' contained under section 1(1) of the Young Persons Act 1933. The appellant's three year old son fell downstairs and was put to bed by him without any medical attention or treatment for his injuries and the child died the next day. The appellant was charged with 'willfully ill-treating' the child. Counsel contended that the section created five different distinct offences and that the prosecution must choose the correct offence. The Court of Appeal held that the words did not create separate and distinct offences and that if an indictment selects one of these particular words and the evidence adduced comes fairly within the ambit of the word selected, then the charge is made out, even though the same conduct might with propriety have been put under a different heading.

Section 33 is another important provision to prevent child neglect which provides that any person who, being a parent or guardian or person having the care of a child, leaves that child without providing reasonably for the child's supervision and care for a period which is unreasonable having regard to the circumstances commits an offence and shall be liable to a fine of up to five thousand ringgit or up to two years' imprisonment or both.

Under Section 43, any person who buys, sells, hires, lets for hire, or otherwise disposes, obtains possession of, procures, receives, harbours, traffics or detains a child for the purpose of prostitution shall be liable to a fine of up to fifteen thousand ringgit or up to fifteen years' imprisonment, or both, and may also under certain circumstances be subject to whipping of not more than six strokes. 
Despite the punishable offences sanctioned under the Act, prosecution in cases of child witness is not easy (Note 11). A conviction cannot stand on the uncorroborated evidence of an unsworn child witness. In the case of sworn child witness the rule of prudence applies, that there must be a warning on the dangers of convicting on such uncorroborated evidence. Corroborative evidence, is confirmatory proof of some fact on which other evidence has been given. The main reason for corroboration is to avoid any possibility of concoction by a child, as a child may tend to fantasize and distort information as well as unable to distinguish between fantasy and reality. The authoritative definition of such evidence is the one laid down in the case of $R v$. Baskerville [1916] $2 \mathrm{~KB} 658$. In this case, Lord Reading said that to amount to corroboration evidence must come from independent evidence which connects the accused with the crime. It must be evidence which implicates him, that is, which confirms in some material particular not only the evidence that the crime has been committed but also that the accused committed it.

Section 118 of the Evidence Act 1950 declares every child to be a competent witness, unless he is prevented from understanding the questions put to him or from giving rational answers to those questions by reason of his tender age.

However, s. 133A of the Act provides that when evidence is given by a child on behalf of the prosecution, the accused shall not be liable to be convicted of the offence unless such evidence is corroborated by some other material evidence. It means that even though a child may understand the question put to him and may be in a position to give rational answers to it, the Court cannot convict the accused unless child's testimony is corroborated by other material evidence implicating the accused. In Tham Kai Yau \& Ors. v. PP [1977] 1 MLJ 174 one of the witnesses called at the trial was the 14 year old son of the deceased. The learned trial Judge allowed him to give evidence on affirmation as he understood the nature and meaning of oath. His evidence showed that the appellants had attacked the deceased with the intention of causing bodily harm to him. Being satisfied that the child witness possessed sufficient intelligence to understand the meaning and significance of an oath, the learned trial Judge accepted his evidence and convicted the appellants. On appeal, it was argued that the jury was not given warning against accepting the evidence of child witness which was not corroborated by any other evidence. The Court of Appeal dismissed the appeal on the ground that the lack of warning to the jury was not fatal as there was substantial corroboration of the evidence of the child witness by the other evidence on record.

\section{Conclusion}

It can be seen that the law regulating the children's rights has become increasingly important and will always continue to evolve. In view of what have been discussed of the Malaysia Child Act 2001, there is a need to review mandatory obligation of reporting imposed on family members, the child minders and the medical practitioners should be extended to all people who have the knowledge of the abuse. This is to ensure that the child is immediately protected upon knowledge of the abuse. Since reporting plays a pivotal role in curbing the crime of abuse, the definition of 'child abuse or neglect' itself should be made public-friendly in order to assist understanding among the public of the term and the Act in specific. Apart from that, the current law in admissibility of child evidence has as well put a great emphasis on the need of corroboration of child's testimony, and this rule of evidence may put the child and his testimony in great disadvantage. It should also be considered that today's children are wiser and more mature and can appreciate matters around them better. The Child Act 2001 is the reflection of the governments' effort to combat child abuse. The continuous development of the law on children reflects a healthy environment to further safeguard, care and protect the children. Last but not least, it is doubtless that apart from legal devices, society is in need of social reforms to better prevent the act of abusing children based on the principle prevention is better than cure.

\section{References}

Abu Bakar Munir. (1995). Evidence for Children: Some Proposals for Reform. Current Law Journal, Vol. 3, lxiii.

Anisah Che Ngah. (2002). Child Abuse: A Socio-Legal Study. Kuala Lumpur: DBP.

Halperin, M. (1979). Helping Maltreated Children. London: The C. V. Mosby Company.

Jal Zabdi Mohd Yusoff. (2002). Child Act 2001: Duty to Report. In Siti Zaharah, Norchaya and Jal Zabdi (Eds), Mimi Kamariah Law Series: Child Act 2001. Kuala Lumpur: Universiti Malaya.

Kempe, C. Henry. (1962). The Battered Child Syndrome, Child Abuse \& Neglect. Journal of American Medical Association, Vol. 9. 
Act

Child Act 2001

Child Protection Act 1991

Children and Young Persons Act 1947

Children Enactment 1992 .No. 1 of 1922, F.M.S. (Cap 158).

Children Ordinance 1927. No. 17 of 1927, Straits Settlements.

Notes

Note 1. Halperin, M. 1979. Helping Maltreated Children. London: The C. V. Mosby Company. p.34.

Note 2. Ibid. p. 77.

Note 3. Halperin, M. 1979. Helping Maltreated Children. p. 35.

Note 4. No. 1 of 1922, F.M.S. (Cap 158).

Note 5. Section 2.

Note 6. No. 17 of 1927, Straits Settlements.

Note 7. Section 2.

Note 8. Kempe, C. Henry. 1962. The Battered Child Syndrome, Child Abuse \& Neglect. Vol 9 in Journal of American Medical Association.

Note 9. See Jal Zabdi Mohd Yusoff. 2002. Akta Kanak-Kanak 2001: Tugas Untuk Memaklumkan in Siti Zaharah, Norchaya dan Jal Zabdi (Eds), Siri Undang-Undang Mimi Kamariah: Akta Kanak-Kanak 2001, Kuala Lumpur: Universiti Malaya. p. 69-84.

Note 10. The Director General, the Deputy Director General, a Divisional Director of Social Welfare, Department of Social Welfare, the State Director of Social Welfare of each of the States and any Social Welfare Officer appointed under section 8 of the Act

Note 11. See Abu Bakar Munir. Evidence For Children: Some Proposals for Reform [1995]3 CLJ lxiii (Aug)

Note 12. Sidek bin Ludan v PP [1995] 3 MLJ 178

Table 1. Case of Child Abuse in Malaysia

\begin{tabular}{|l|c|c|}
\hline \multicolumn{1}{|c|}{ Year } & Total Cases & Monthly Average \\
\hline 2005 & 2236 & 186 \\
\hline 2008 & 5774 & 479 \\
\hline 2009 (Jan-July) & 2193 & 313 \\
\hline
\end{tabular}

Source: Royal Malaysia Police 